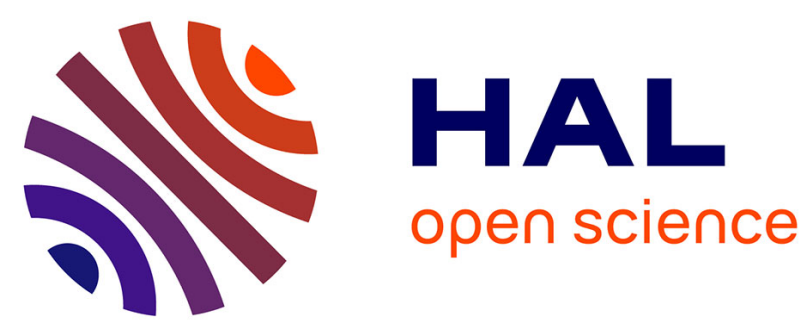

\title{
Structurally complex metallic coatings in the Al-Cu system and their orientation relationships with an icosahedral quasicrystal
}

Thomas Duguet, Samuel Kenzari, Valérie Demange, Thierry Belmonte, Jean-Marie Dubois, Vincent Fournée

\section{To cite this version:}

Thomas Duguet, Samuel Kenzari, Valérie Demange, Thierry Belmonte, Jean-Marie Dubois, et al.. Structurally complex metallic coatings in the $\mathrm{Al}-\mathrm{Cu}$ system and their orientation relationships with an icosahedral quasicrystal. Journal of Materials Research, 2010, 25 (4), pp.764-772. 10.1557/JMR.2010.0101 . hal-00831639

\section{HAL Id: hal-00831639 \\ https://hal.science/hal-00831639}

Submitted on 7 Jun 2013

HAL is a multi-disciplinary open access archive for the deposit and dissemination of scientific research documents, whether they are published or not. The documents may come from teaching and research institutions in France or abroad, or from public or private research centers.
L'archive ouverte pluridisciplinaire HAL, est destinée au dépôt et à la diffusion de documents scientifiques de niveau recherche, publiés ou non, émanant des établissements d'enseignement et de recherche français ou étrangers, des laboratoires publics ou privés. 


\title{
Structurally complex metallic coatings in the Al-Cu system and their orientation relationships with an icosahedral quasicrystal
}

\author{
Thomas Duguet and Samuel Kenzari \\ Institut Jean Lamour, UMR 7198, CNRS-Nancy Université-UPV Metz, Ecole des Mines de Nancy, \\ 54042 Nancy Cedex, France \\ Valérie Demange \\ Sciences Chimiques de Rennes, UMR 6226, CNRS-Université Rennes 1, Campus de Beaulieu, \\ 35042 Rennes Cedex, France \\ Thierry Belmonte, Jean-Marie Dubois, and Vincent Fournée ${ }^{\text {a) }}$ \\ Institut Jean Lamour, UMR 7198, CNRS-Nancy Université-UPV Metz, Ecole des Mines de Nancy, \\ 54042 Nancy Cedex, France
}

(Received 6 November 2009; accepted 4 January 2010)

\begin{abstract}
Quasicrystals have been identified as alloys possessing unusually low surface energy. This results in poor adhesion properties of quasicrystalline coatings when deposited on metallic substrates, hindering the development of these new materials for technological applications. Here we investigate the possible use of complex Al-Cu metallic phases as interface layers to accommodate the structural and electronic mismatch between a quasicrystalline coating and a metallic substrate and improve adhesion. First, we show that all stable low-temperature phases of the Al-Cu system can be grown as thin films using DC magnetron sputtering. Among the various possible phases, we select the $\gamma$-brass $\gamma-\mathrm{Al}_{4} \mathrm{Cu}_{9}$ as a promising candidate for the interface layer. Then the $\gamma-\mathrm{Al}_{4} \mathrm{Cu}_{9}$ phase is grown on the fivefold surface of an icosahedral ( $i-)$ Al-Pd-Mn quasicrystal. The interface is investigated by transmission electron microscopy and shows a clear texturing of the film. The grains exhibit rotational epitaxy with the substrate. We find that the interface is mainly composed of a $\beta$-phase of unknown chemical composition and sometimes exhibits $\gamma$ grains in direct contact with the quasicrystalline substrate. Occasionally, we observe a fourth phase at the $\beta / \gamma$ interface, identified as $\beta_{1}$, possessing a lattice parameter $a_{\beta 1}$ equal to $2 a_{\beta}$ and $2 / 3 a_{\gamma}$.
\end{abstract}

\section{INTRODUCTION}

In the last decade, there has been an intense renewal of interest for binary Al-transition metal(s) systems containing complex metallic alloys (CMAs) with giant unit cells related to quasicrystalline phases. ${ }^{1-10}$ This was motivated in part by the possibility of developing CMAs as new coating materials with low friction, reduced adhesion, and good corrosion resistance for technological applications. ${ }^{11-13}$ Those surface properties are related to the peculiar electronic structure of CMAs characterized by a pseudogap at the Fermi level, usually associated with poor metallic behavior. Quasicrystals represent the ultimate case of CMAs, possessing long range order but no translation periodicity together with forbidden rotational symmetry, such as fivefold or tenfold symmetry. ${ }^{14}$

Although the surface properties of CMAs and quasicrystals are very promising, ${ }^{15}$ their development as functional coatings has been hindered by the poor adhesion

\footnotetext{
a) Address all correspondence to this author.

e-mail: vincent.fournee@mines.inpl-nancy.fr

DOI: $10.1557 / J M R .2010 .0101$
}

observed on metallic substrates. Extensive studies of the wetting and adhesive properties of quasicrystalline and CMA surfaces have shown that this is related to a relatively low surface energy compared to metallic systems, especially transition metals. One possibility to circumvent this problem is to develop an interfacial layer such as obtaining a gradient of properties between the substrate and the surface. ${ }^{16}$ This interface layer should be an intermetallic compound presenting electronic and crystallographic characteristics that are intermediate between those of a simple metal and a quasicrystal. This condition is usually met by the so-called approximant phases, which have a periodic structure with giant unit cells and a local order similar to that of the quasicrystalline phase.

In this article, we report a study of the formation of CMA compounds in the Al-Cu system by reactive diffusion in the solid state between bilayers deposited by DC magnetron sputtering. The various phase transformations induced by reactive diffusion between $\mathrm{Al} / \mathrm{Cu}$ bilayers have been investigated in previous reports. ${ }^{17-31}$ Here we mainly focus on the formation of CMA phases existing in 
the $\mathrm{Al}-\mathrm{Cu}$ system, namely the $\gamma$-brass $\mathrm{Al}_{4} \mathrm{Cu}_{9}{ }^{1}$ and the orthorhombic $\zeta-\mathrm{Al}_{3} \mathrm{Cu}_{4}{ }^{2,7}$ compounds. These two phases were previously identified as approximant phases of quasicrystals by Dong et al. ${ }^{3,32}$ They are not true geometrical approximants, but they contain similar valence electron concentrations compared to the icosahedral $\mathrm{Al}-\mathrm{Cu}-\mathrm{Fe}$ quasicrystal and exhibit locally pseudo-pentagonal configurations and distorted icosahedra. The two compounds are stable at low temperature according to the phase diagram. ${ }^{33}$ Their stabilization is attributed to a HumeRothery mechanism similar to the one taking place in the icosahedral phase. The number of atoms per unit cell is larger compared to most simple metals ( 52 for $\gamma-\mathrm{Al}_{4} \mathrm{Cu}_{9}$ and 83 for $\zeta-\mathrm{Al}_{3} \mathrm{Cu}_{4}$ ), but smaller compared to most CMAs. The two compounds are described as superstructures of the $\beta-\mathrm{AlCu}$ phase $(\mathrm{CsCl}$ structure type). They thus represent an intermediate complexity between simple metals and quasicrystals. In addition, recent ultra high vacuum studies have shown that the $\gamma-\mathrm{Al}_{4} \mathrm{Cu}_{9}$ phase can be grown on the fivefold surface of either $\mathrm{Al}-\mathrm{Cu}-\mathrm{Fe}$ or Al-Pd-Mn icosahedral quasicrystals, ${ }^{16,34}$ with clear rotational epitaxy with the substrates. This supports the idea that such compounds could be used as a buffer layer to accommodate the interface between a quasicrystalline coating and a simple metal substrate.

The article is organized as follows. We first provide experimental details in Sec. II. In Sec. III, we describe the formation of selected stable compounds of the $\mathrm{Al}-\mathrm{Cu}$ phase diagram by varying the thickness of the elemental $\mathrm{Al}$ and $\mathrm{Cu}$ layers deposited on various substrates. In Sec. $\mathrm{IV}$, we form a coating of the $\gamma-\mathrm{Al}_{4} \mathrm{Cu}_{9}$ on an icosahedral $(i-) \mathrm{Al}-\mathrm{Pd}-\mathrm{Mn}$ single grain quasicrystal oriented normal to one of its fivefold axes, and the interface is investigated by transmission electron microscopy (TEM). Finally, we discuss the orientation relationships at the crystalquasicrystal interface.

\section{EXPERIMENTAL DETAILS}

The $\mathrm{Al} / \mathrm{Cu}$ films were grown by $\mathrm{DC}$ magnetron sputtering. Three different types of substrate have been used for deposition. The first one is an $\mathrm{Si}(100)$ wafer on which the native oxide was intentionally kept in order to act as a diffusion barrier and avoid intermixing with Si. The second one is a 304L steel substrate, polished using diamond paste down to $1 \mu \mathrm{m}$ and cleaned with acetone in an ultrasonic bath, then with methanol. In addition, substrates are cleaned with ethanol using optical paper just before loading into the sputtering system. The third type of substrate is a single grain quasicrystal prepared as explained later in Sec. IV.

The base pressure in the sputtering system is $1.10^{-7}$ mbar. Films are deposited at a pressure of $2.10^{-2}$ mbar in an atmosphere containing $10 \% \mathrm{H}_{2}-90 \%$ Ar. The sputtering system is equipped with three inde- pendent magnetrons focused at the center of the substrate holder and inclined by $30^{\circ}$ with respect to the substrate surface normal. The target to substrate distance is set equal to $10 \mathrm{~cm}$ and the sample rotates at $28 \mathrm{rpm}$ during deposition to ensure homogeneity. $\mathrm{Al} / \mathrm{Cu}$ bilayers are deposited at room temperature. In the case of the steel substrate, a radio-frequency biasing is first applied to remove the oxide layer. A self-bias of $-200 \mathrm{~V}_{\mathrm{DC}}$ is measured on the substrate holder for a power of $43 \mathrm{~W}_{\mathrm{RF}}$. This allows the recovery of metallic iron at the surface and in addition should favor interdiffusion between substrate and film, thus enhancing adherence. ${ }^{35}$ Similarly, both $\mathrm{Al}$ and $\mathrm{Cu}$ targets are cleaned before deposition. This is achieved by sputtering the targets for $5 \mathrm{~min}$ (using $80 \mathrm{~W}_{\mathrm{DC}}$ and $100 \mathrm{~W}_{\mathrm{DC}}$ for $\mathrm{Cu}$ and $\mathrm{Al}$ targets, respectively), the shutters being closed. The purity of the elemental targets is 99.99 and $99.95 \%$ for $\mathrm{Al}$ and $\mathrm{Cu}$, respectively. The total thickness of the $\mathrm{Al} / \mathrm{Cu}$ bilayers is equal to $1 \mu \mathrm{m}$. After deposition, the bilayers are annealed in situ $\left(220^{\circ} \mathrm{C}\right.$ for $1 \mathrm{~h}$ ) in a gas flow with a pressure of $2.10^{-2}$ mbar using a PBN heater located at the back side of the substrate holder. The temperature has been calibrated using a thermocouple sealed inside a $3 \mathrm{~mm}$ thick $\mathrm{Cu}$ sample within a temperature range from $20^{\circ} \mathrm{C}$ to $400{ }^{\circ} \mathrm{C}$.

The deposition rates have been determined by measuring layer thicknesses on cross sections of $\mathrm{Al} / \mathrm{Cu} / \mathrm{Si}(100)$ samples by scanning electron microscopy (SEM) in secondary electron and backscattered modes (Philips XL30). We have checked that the layer thicknesses are constant over the deposition area, although local height variations are observed for $\mathrm{Al}$ thin films resulting from anisotropy of grain growth. The deposition rates thus determined are equal to 650 and $1480 \mathrm{~nm} \cdot \mathrm{h}^{-1}$ for $\mathrm{Al}$ and $\mathrm{Cu}$, respectively, within our experimental conditions.

The various phases formed after annealing are identified using grazing-incidence x-ray diffraction (GI-XRD) at an incident angle of $3^{\circ}$ with $\mathrm{Co}_{\mathrm{K} \alpha}$ radiation $(\lambda=$ $1.78897 \AA$, INEL CPS120 instrument, Artenay, France) and energy dispersive spectroscopy (EDS) measurements performed at $15 \mathrm{keV}$ in the SEM (FEI XL30, Eindhoven, The Netherlands) to avoid contribution from the substrate.

Samples for TEM were prepared by mechanical polishing to a thickness of $40 \mu \mathrm{m}$ followed by an ion milling process $\left(\mathrm{Ar}^{+}, 3 \mathrm{kV}\right.$, Gatan PIPS device, Pleasanton, $\left.\mathrm{CA}\right)$. TEM was performed on a $\mathrm{LaB}_{6}$ Philips CM200 instrument (Eindhoven, The Netherlands) with a voltage of $200 \mathrm{kV}$. Electron energy loss spectroscopy (EELS) was carried out with a PEELS 666 Gatan device coupled to the TEM.

\section{CHARACTERIZATION}

As-deposited films of the pure elements do not show any contamination within the detection limits of EDS. Pure Al thin films have a white color, which is not due to oxidation of the $\mathrm{Al}$ but to texturing. This was verified 
ex situ by x-ray photoemission spectroscopy (XPS). The as-loaded $\mathrm{Al}$ film exhibits a clear doubling of the $\mathrm{Al} 2 p$ core level with a metallic component at $72.6 \mathrm{eV}$ binding energy (BE) and an oxide component at $74.9 \mathrm{eV} \mathrm{BE}$. After sputtering the surface $\left(\mathrm{Ar}^{+}, 3 \mathrm{kV}, 30 \mathrm{~min}\right)$, the oxide component almost completely disappeared, showing that the $\mathrm{Al}$ oxide was limited to the first atomic layers as a result of air exposure during sample transfer from the sputtering system to the XPS chamber.

Figure 1 shows selected SEM images of as deposited $\mathrm{Al} / \mathrm{Cu}$ bilayers. Texturing of a pure $\mathrm{Al}$ thin film is obvious in Fig. 1(a). Copper thin films exhibit a columnar morphology, common for physical vapor deposition at this pressure (not shown). Columnar grains are visible in the backscattered SEM image of the $\mathrm{Al} / \mathrm{Cu}$ bilayer shown in Fig. 1(b) for $t_{\mathrm{Al}} / t_{\mathrm{Cu}}=1.06$. A cross-sectional image of a $\gamma-\mathrm{Al}_{4} \mathrm{Cu}_{9}$ coating is shown in Fig. 1(c). It has been obtained after annealing an $\mathrm{Al} / \mathrm{Cu}$ bilayer with thickness ratio $t_{\mathrm{Al}} / t_{\mathrm{Cu}}=1.06$. Observation of the fracture profile reveals that the $\mathrm{Al}-\mathrm{Cu}$ compounds are dense and brittle. The total thickness of the coating is basically unchanged upon annealing, suggesting that as-deposited $\mathrm{Al}$ and $\mathrm{Cu}$ elemental films are reasonably dense, although some porosity can be observed at the surface as shown in Fig. 1(d) for the case of the $\gamma-\mathrm{Al}_{4} \mathrm{Cu}_{9}$ film.

Several bilayers have been deposited either on $\mathrm{Si}$ wafers or on steel substrates with different thickness ratios $t_{\mathrm{Al}} / t_{\mathrm{Cu}}$ such as to form the different stable phases reported in the phase diagram. Figure 2 shows the corresponding GI-XRD spectra recorded after annealing the

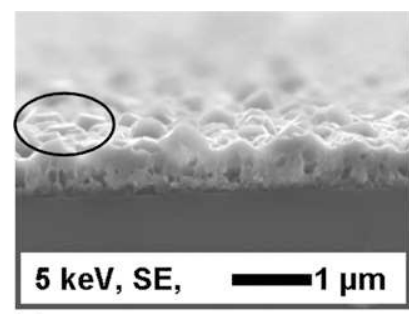

(a)

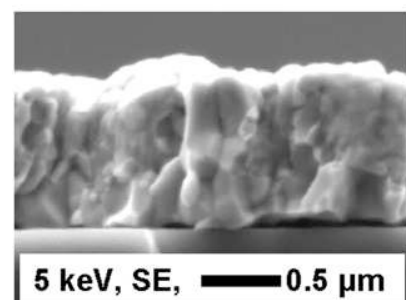

(c)

FIG. 1. Cross-section scanning electron micrographs of $\mathrm{Al}-\mathrm{Cu}$ thin films deposited on $\mathrm{Si}(100)$ equipped with its native oxide: (a) pure $\mathrm{Al}$ thin film with an average thickness of $650 \mathrm{~nm}$. The circled region shows faceting of the $\mathrm{Al}$ grains; (b) bilayer of $\mathrm{Al}(550 \mathrm{~nm})$ and $\mathrm{Cu}(1350 \mathrm{~nm})$, shown in back-scattered electron mode to see the Z-contrast; (c) annealed $\mathrm{Al}(530 \mathrm{~nm}) / \mathrm{Cu}(500 \mathrm{~nm})$ sample determined to be $\gamma-\mathrm{Al}_{4} \mathrm{Cu}_{9}$ with a thickness of $1 \mu \mathrm{m}$ after annealing. (d) Top-view scanning electron micrograph of an annealed $\mathrm{Al}(530 \mathrm{~nm}) / \mathrm{Cu}(500 \mathrm{~nm})$ sample. bilayers. The phases identified in each sample are reported in Table I. Semi-quantitative chemical compositions of the various coatings measured by EDS and secondary ion mass spectroscopy (SIMS) are also listed in Table I as a function of $t_{\mathrm{Al}} / t_{\mathrm{Cu}}$. We note that compositions measured by EDS show a higher $\mathrm{Cu}$ content compared to the stability domains of the phases identified by GI-XRD. This could result from an inhomogeneous composition along the surface normal due to incomplete alloying during the thermal cycle used in this set of experiments. Thus we have performed additional measurements using SIMS. Composition profiles indicate that some coatings $\left(t_{\mathrm{Al}} / t_{\mathrm{Cu}}=2.82,1.7\right.$, and 1.55) are indeed inhomogeneous over the whole film thickness. However, the concentration profiles are constant over the first $400 \mathrm{~nm}$ below the surface. Hence the compositions measured by SIMS reported in Table I are those measured in this limited

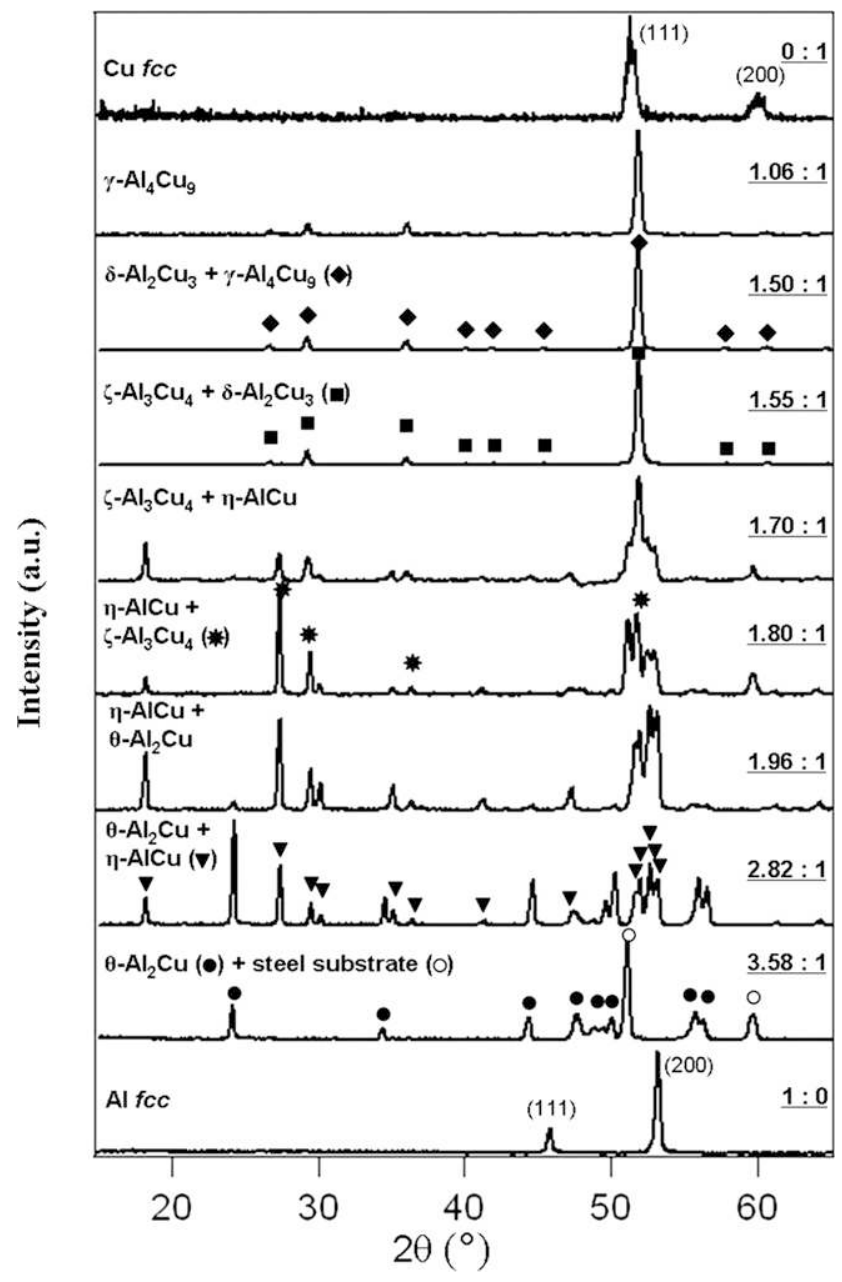

FIG. 2. X-ray diffraction patterns $\left(\lambda_{\mathrm{K} \alpha}=1.78897 \AA\right)$ of $\mathrm{Al}-\mathrm{Cu}$ bilayers after annealing for $1 \mathrm{~h}$ at $220{ }^{\circ} \mathrm{C}$, either on steel or $\mathrm{Si}(100)$ substrates. The thickness ratio $t_{\mathrm{Al}} / t_{\mathrm{Cu}}$ is underlined next to each pattern. All samples have a thickness of $1 \mu \mathrm{m}$ except the one corresponding to $t_{\mathrm{Al}} / t_{\mathrm{Cu}}=3.58$ which is only $500 \mathrm{~nm}$ thick. For each pattern, the main lines of the majority phase are marked with symbols. 
TABLE I. Semi-quantitative chemical composition of thin films determined by EDS and SIMS as a function of thickness ratio $t_{\mathrm{Al}} / t_{\mathrm{Cu}}$ and corresponding crystalline phases identified by GI-XRD. The composition measured by EDS is averaged over the first micron while that measured by SIMS is averaged over a thickness of only $0.4 \mu \mathrm{m}$ below the surface. The last column gives the Cu concentration expected from the bulk composition of the identified phases.

\begin{tabular}{|c|c|c|c|c|}
\hline$t_{\mathrm{Al}} / t_{\mathrm{Cu}}$ & XRD & $\operatorname{EDS}(\mathrm{Cu}$ at.\%) & Surface composition determined by SIMS (Cu at.\%) & $\mathrm{Cu}$ at. $\%$ from Ref. 23 \\
\hline 3.58 & $\theta-\mathrm{Al}_{2} \mathrm{Cu}$ & \multicolumn{2}{|c|}{ missing data, single phase $\theta-\mathrm{Al}_{2} \mathrm{Cu}$ domain $\rightarrow$} & 31.9 to 33 \\
\hline 2.82 & $\theta-\mathrm{Al}_{2} \mathrm{Cu}+\eta-\mathrm{AlCu}$ & 49.3 & 51.5 & \multirow{2}{*}{33 to 49.8} \\
\hline \multirow[t]{2}{*}{1.96} & $\theta-\mathrm{Al}_{2} \mathrm{Cu}+\eta-\mathrm{AlCu}$ & 55.8 & 47.3 & \\
\hline & & & single-phase $\theta$-AlCu domain $\rightarrow$ & 49.8 to 52.3 \\
\hline 1.8 & $\zeta-\mathrm{Al}_{3} \mathrm{Cu}_{4}+\eta-\mathrm{AlCu}$ & $\begin{array}{l}58.7 \\
62.1\end{array}$ & $\begin{array}{r}51.5 \\
51.5\end{array}$ & 52.3 to 55.2 \\
\hline \multirow[b]{2}{*}{1.55} & \multirow[b]{2}{*}{$\zeta-\mathrm{Al}_{3} \mathrm{Cu}_{4}+\delta-\mathrm{Al}_{2} \mathrm{Cu}_{3}$} & \multirow[b]{2}{*}{62.6} & single-phase $\zeta-\mathrm{Al}_{3} \mathrm{Cu}_{4}$ domain $\rightarrow$ & 55.2 to 56.3 \\
\hline & & & $\begin{array}{c}57.0 \\
\text { single-phase } \delta-\mathrm{Al}_{2} \mathrm{Cu}_{3} \text { domain } \rightarrow\end{array}$ & $\begin{array}{l}56.3 \text { to } 59.3 \\
59.3 \text { to } 61.9\end{array}$ \\
\hline 1.5 & $\delta-\mathrm{Al}_{2} \mathrm{Cu}_{3}+\gamma-\mathrm{Al}_{4} \mathrm{Cu}_{9}$ & 67.6 & 63.0 & 61.9 to 62.5 \\
\hline 1.06 & $\gamma-\mathrm{Al}_{4} \mathrm{Cu}_{9}$ & 68.1 & 62.3 & 62.5 to 69 \\
\hline
\end{tabular}

surface region. These chemical compositions are in better agreement with the composition of the bulk phases. These measurements indicate that either longer annealing times or higher annealing temperatures are required to achieve a complete alloying of the bilayers. Because of these limitations, the compositions given here are only semi-quantitative.

We note that the choice of the substrate-either oxidized $\mathrm{Si}(100)$ or sputtered steel — has no noticeable effect on the phases formed upon low temperature annealing $\left(220^{\circ} \mathrm{C}\right)$, as characterized by GI-XRD. We also mention that we did not detect by EDS any chemical species that could have diffused from the substrate into the film upon annealing. However, the adherence of the coatings on $\mathrm{Si}(100)$ wafers is poor: coatings either spontaneously peel off or can be removed using an adhesive tape, which is convenient for further TEM investigations. On the contrary, the adherence of the coatings on sputtered steel substrates is very good, as evidenced by subsequent tribological tests performed on these samples (data not presented here).

\section{ORIENTATION RELATIONSHIPS BETWEEN $\gamma-\mathrm{Al}_{4} \mathrm{Cu}_{9}$ AND I-Al-Pd-Mn}

A $1 \mu \mathrm{m}$ thick film of the $\gamma-\mathrm{Al}_{4} \mathrm{Cu}_{9}$ has been prepared on the fivefold surface of an icosahedral (i-)Al-Pd-Mn quasicrystal following the same procedure as described above.

The micrograph shown in Fig. 3 represents the typical microstructure of the film and its interface with the substrate. The zone with the brightest contrast corresponds to the film. The micrograph shows that the film-substrate interface is not flat, suggesting interdiffusion has occurred during further growth of the film. Electrondiffraction patterns (EDP) allow the identification of the various phases. They were recorded at different substrate orientations. We identify three of them: the $\gamma-\mathrm{Al}_{4} \mathrm{Cu}_{9}$ phase $\left(a_{\text {exp }}=8.60 \AA\right)$ in the film area and the icosahedral

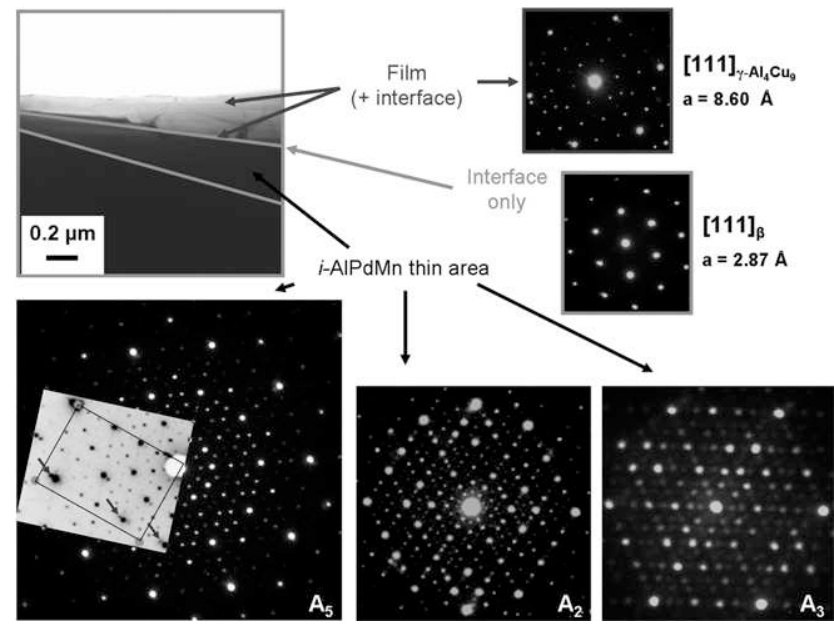

FIG. 3. Typical brightfield micrograph of the sample with thickness ratio $t_{\mathrm{Al}} / t_{\mathrm{Cu}}=1.06$ and electron-diffraction patterns showing the different structures in the different zones separated by solid lines.

phase in the substrate area, but also an ordered cubic $\beta$-phase $\left(a_{\exp }=2.87 \AA\right)$ of unknown composition which is located exclusively at the interface. The $\gamma-\mathrm{Al}_{4} \mathrm{Cu}_{9}$ phase sometimes appears directly at the interface, with no extra phase, but this situation was found to be the exception rather than the rule.

The diffraction pattern of the quasicrystalline phase along the fivefold axis $\left(\mathrm{A}_{5}\right)$ exhibits some disorder depending on the probed area (Fig. 3). The inset shows part of a second pattern recorded in a thin area of the quasicrystal using inverse contrast. Arrows indicate the doubling of intense spots along a specific direction. This may result from the ion bombardment that can degrade the sample and lead to the formation of structures with lower symmetry. ${ }^{36,37}$ In the case of icosahedral phases, these structures possess either pentagonal, tetrahedral, trigonal, or decagonal symmetry. ${ }^{38}$ These kinds of defects may also be intrinsic to the single grain quasicrystal. In both cases, such a doubling of the spots is 
explained by linear phasonic deformation. ${ }^{38}$ Additional spots can be distinguished in the diffraction pattern shown $\left(\mathrm{A}_{5}\right.$ in Fig. 3). They define a rectangular mesh with a lattice parameter of $3.01 \AA$. This could correspond to the $\beta-\mathrm{Al}(\mathrm{Pd}, \mathrm{Mn})$ phase reported in Bolliger et al. ${ }^{39}$ These two different defects appear in thin areas of the sample, suggesting that they are induced by the ion bombardment used during the thinning process. We emphasize that this $\beta-\mathrm{Al}(\mathrm{Pd}, \mathrm{Mn})$ phase (with lattice parameter $a=3.01 \AA$ ) is located within the substrate area and is different from the $\beta$ phase identified at the interface (with lattice parameter $a=2.87 \AA$ ). This latter one may have formed either during the sputtering of the substrate before thin film deposition or possibly because of incomplete alloying during the annealing of the bilayer, or a combination of the two. In an attempt to discriminate between these two possibilities, we have performed additional EELS measurements. It turns out that the substrate contains exclusively $\mathrm{Al}, \mathrm{Pd}$, and $\mathrm{Mn}$ and that both interface and film contain $\mathrm{Al}$ and $\mathrm{Cu}$. However, we cannot exclude the presence of $\mathrm{Pd}$ and/or $\mathrm{Mn}$ at the interface that could not have been detected by EELS due to a too large thickness in this area. Nevertheless, $\mathrm{Cu}$ is clearly identified at the interface and within the film. However, the intensities of $\mathrm{Cu} \mathrm{L}_{2,3}$ and $\mathrm{M}_{2,3}$ spectra recorded at the interface are reduced compared to the film, that is, the $\mathrm{Cu}$ content of the $\beta$ phase is lower than that of the $\mathrm{Al}_{4} \mathrm{Cu}_{9}$ film $\left([\mathrm{Cu}]_{\beta}<69\right.$ at.\%). The existence of various $\beta$ phases was reported in all relevant phase diagrams, including $\beta-\mathrm{AlCu}_{3}$ with $\mathrm{A} 2$ structure type, as well as $\beta$-Al-Mn, $\beta$-Al-Pd, $\beta$-Al-Pd-Mn, $\beta-\mathrm{Al}-\mathrm{Cu}-\mathrm{Pd}$, and $\beta$-Al-Cu-Mn. ${ }^{40}$ Based on EELS measurements, the two possible candidates are the high-temperature $\beta-\mathrm{AlCuPd}_{2}$ phase with $a=3.003 \AA$ and the $\beta-\mathrm{Al}_{20} \mathrm{CuMn}$ phase with $a=2.984 \AA$. We cannot rule out either the formation of other metastable phases or of quaternary phases.

In a recent study by Bielmann et al., it was found that the $\gamma-\mathrm{Al}_{4} \mathrm{Cu}_{9}$ phase could be formed as a surface alloy by annealing a $\mathrm{Cu}$ thin film deposited on the fivefold surface of $i$-Al-Pd-Mn through diffusion of $\mathrm{Al}$ in the $\mathrm{Cu}$ film. ${ }^{34}$ No traces of Pd could be detected by Auger spectroscopy in the near surface region, although the annealing temperature used in this study was $350{ }^{\circ} \mathrm{C}$, that is, higher than the temperature used in the present work. This suggests that diffusion of Pd at the interface is less favorable compared to $\mathrm{Al}$ diffusion. This is consistent with the lower enthalpy of formation of the $\gamma-\mathrm{Al}_{4} \mathrm{Cu}_{9}$ phase, $\Delta H_{\mathrm{f}}\left(\gamma-\mathrm{Al}_{4} \mathrm{Cu}_{9}\right)=-23.0 \mathrm{~kJ} \cdot \mathrm{mol}^{-1}$ compared to other $\mathrm{Cu}-$ Pd phases, such as $\Delta H_{\mathrm{f}}(\beta-\mathrm{CuPd})=-13.7 \mathrm{~kJ} \cdot \mathrm{mol}^{-1}{ }^{41}$ In the present work, the $\mathrm{Cu}$ layer and the substrate are initially separated by a $500 \mathrm{~nm}$-thick Al layer. Reactive diffusion at $220{ }^{\circ} \mathrm{C}$ between elemental multilayers of $\mathrm{Al} / \mathrm{Cu}$ and $\mathrm{Al} / \mathrm{Mn}$ is known to promote the formation of alloyed thin films. ${ }^{42}$ At room temperature, those two elements deposited on $\mathrm{Al}$ or coated with $\mathrm{Al}$ by magnetron sputtering exhibit similar values of interdiffusion lengths. Those lengths are larger than the one reported for the $\mathrm{Al} / \mathrm{Pd}$ system. ${ }^{35}$ Therefore, the formation of the $\beta$ phase at the interface could result from the diffusion of $\mathrm{Cu}$ from the upper layer and Mn from the underlying substrate into the $\mathrm{Al}$ layer, leading to the formation of a ternary $\beta-\mathrm{Al}-\mathrm{Cu}-\mathrm{Mn}$ phase. The limited grain size at the interface would then be induced by an incident flux of $\mathrm{Cu}$ atoms largely superior to the $\mathrm{Mn}$ atoms flux coming from an alloyed substrate with a low Mn content. Moreover, Mn diffusion kinetics would be limited due to the lack of defects in the single crystal, in comparison to the $\mathrm{Cu}$ atoms diffusing from a polycrystalline layer with many diffusion paths (grain boundaries, dislocations, etc.). Assumptions concerning the formation of the interfacial $\beta$ phase are difficult to express because of the many possibilities for its formation. The mechanism can be much more complicated and we do not possess enough kinetics and thermodynamics data to go further in the discussion. Consequently, we now focus on the orientation relationships (ORs) between the different structures.

The transmission electron micrographs shown in Figs. 4 to 8 were recorded in bright field mode. Therefore, the substrate oriented along a zone axis as well as grains in rotational epitaxy with respect to the substrate appear with a dark contrast. Note that due to the fivefold symmetry of the substrate, rotational epitaxy of either the $\beta$-CsCl or the $\gamma-\mathrm{Al}_{4} \mathrm{Cu}_{9}$ phase implies that only two out of three crystallographic axes are aligned with a dense axis of the substrate. ${ }^{16,34,43-45}$ Hence, the film should not appear as completely dark in these images. Also, grains of the film appearing with a bright contrast can nevertheless have ORs with the substrate, albeit with another substrate axis, different from the zone axis considered.

Figure 4(a) shows a micrograph together with EDPs of the various phases recorded when the substrate is along an $\mathrm{A}_{5}$ zone axis [Fig. 4(b)]. The diffraction pattern corresponding to the $\beta$ phase was recorded at the substratefilm interface and corresponds to a [111] axis of the $\beta$ phase [Fig. 4(c)]. The EDP performed within a grain of the $\gamma$ phase corresponds to a [111] axis [Fig. 4(d)]. Experimental angles between the $\{110\}$ planes take values of either $62.5^{\circ}$ or $57.5^{\circ}$ instead of the expected $60^{\circ}$ angle. This corresponds to an elongation by $4 \%$ along the $[-110]$ direction. Such a deformation of the $\gamma$ phase can have a variety of origins, including thermal strain induced by the mismatch between the expansion coefficients of film and substrate or internal strain (due to, e.g., incommensurability between substrate and film, columnar morphology of the film, or Ar atom trapping resulting from ion bombardment, etc.). The lattice parameter of the $\gamma$ phase is measured at $8.60 \AA$, that is, $1.3 \%$ smaller compared to the bulk lattice parameter of $8.71 \AA .{ }^{40}$ The EDP of the quasicrystalline substrate is used to determine the ORs. 


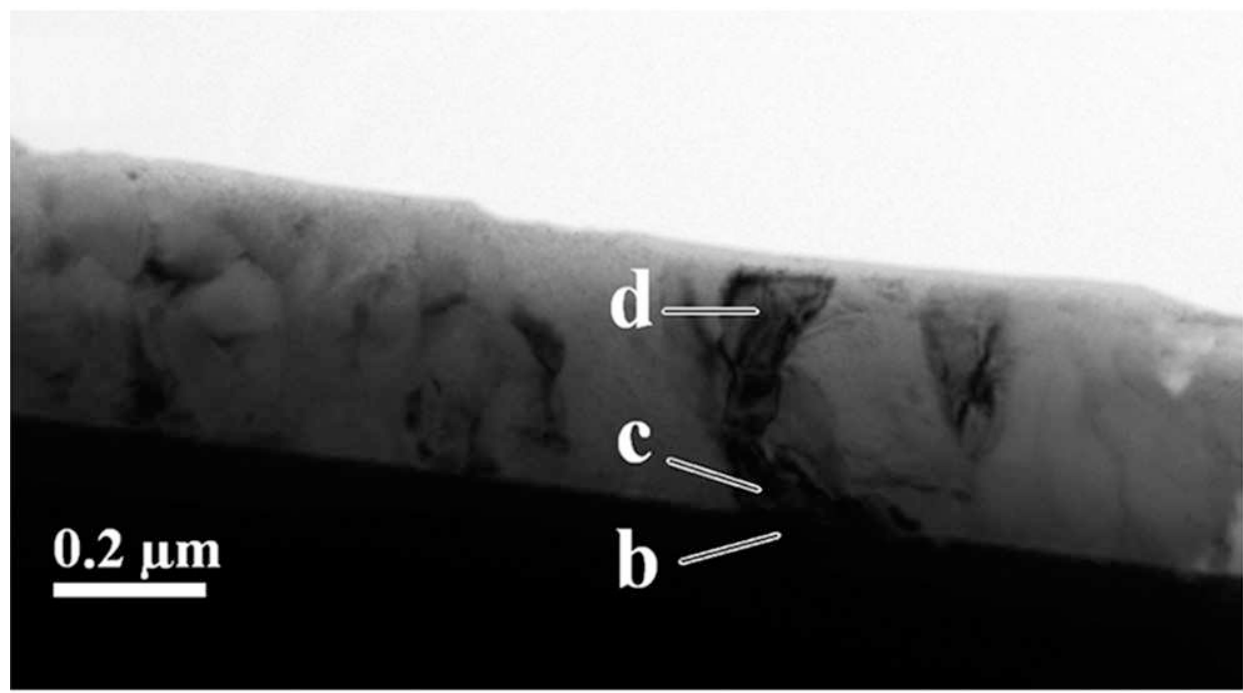

(a)

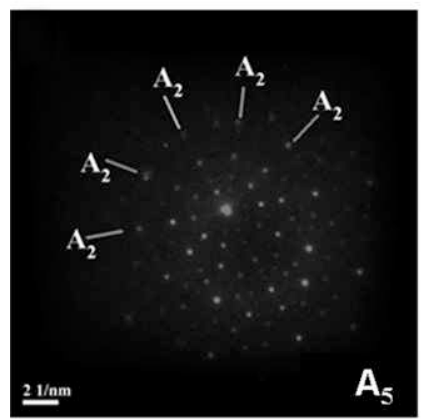

(b)

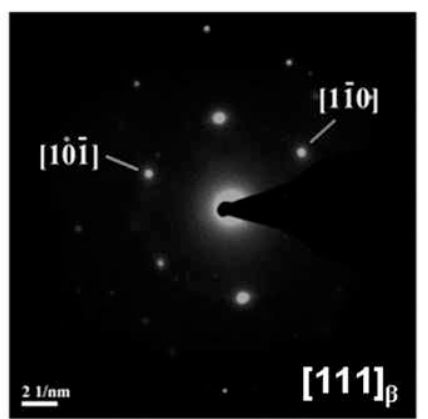

(c)

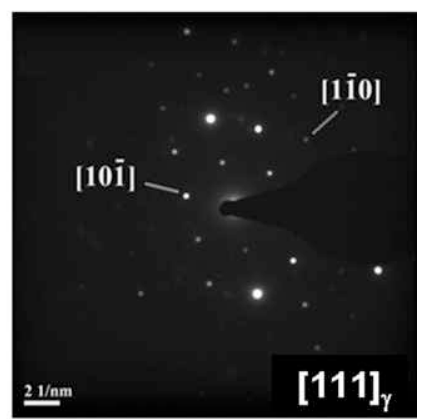

(d)

FIG. 4. (a) Bright field micrograph of a sample with thickness ratio $t_{\mathrm{Al}} / t_{\mathrm{Cu}}=1.06$ and substrate oriented along an $\mathrm{A}_{5}$ axis. (b) EDPs of icosahedral quasicrystalline substrate, (c) $\beta$-phase along the [111] axis, and (d) $\gamma$-phase along the [111] axis.

Figure 5(a) shows another grain of the $\gamma$-phase grain with its [111] axis parallel to the $A_{5}$ axis of the substrate. The diffraction pattern shown in Fig. 5(b) has been obtained by tilting the sample by $14.8^{\circ}$ to observe a [100] zone axis of the $\gamma$-phase. Two different phases contribute to this complex EDP: the $\gamma$ phase and another cubic phase with lattice parameter $a=5.72 \AA$, both aligned along their [100] direction. The latest corresponds to a metastable phase, named $\beta_{1}$, with $a_{\beta 1}=2 a_{\beta}=2 / 3 a_{\gamma}$ and containing 16 atoms in the cubic unit cell. Its formation has already been reported in $\mathrm{Al}-\mathrm{Cu}$ alloys containing $40-50$ at.\% $\mathrm{Cu}$ obtained by rapid quenching and annealing at $750{ }^{\circ} \mathrm{C}$. ${ }^{46}$ The interface is thus composed of a complex microstructure, containing a variety of cubic phases of increasing complexity, with $a_{\beta_{0}}=2.87 \AA, a_{\beta 1}=5.72\left(\approx 2 a_{\beta}=5.74 \AA\right)$ and $a_{\gamma}=8.60 \AA$ ( $\left.\approx 3 a_{\beta}=8.61 \AA\right)$.

Figure 6 shows EDPs of the $\gamma$ phase in direct contact with the substrate oriented normal to one of its twofold axes $\left(\mathrm{A}_{2}\right)$. The $\gamma$ phase has its [111] axis parallel to the twofold substrate axis in this case. The micrograph and EDPs shown in Fig. 7 reveal the ORs between the $\beta$ phase and the substrate at the interface, with the substrate oriented along a twofold axis. The grain of the $\gamma$

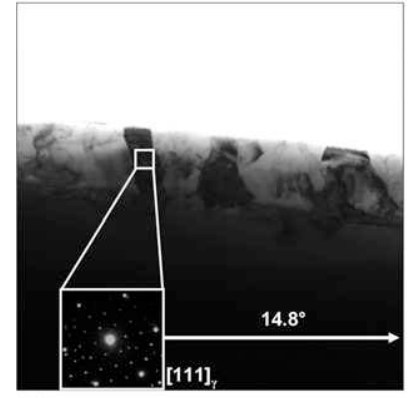

(a)

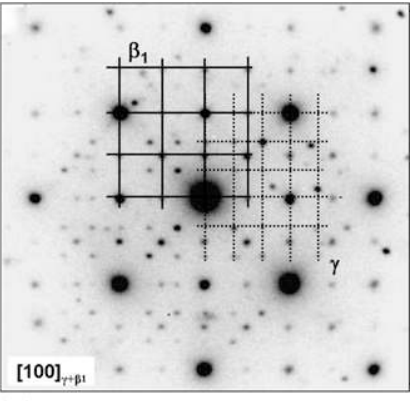

(b)
FIG. 5. Bright field micrograph of the sample with thickness ratio $t_{\mathrm{Al}} /$ $t_{\mathrm{Cu}}=1.06$ observed along an $\mathrm{A}_{5}$ zone axis with a $\gamma$ grain in [111] orientation (a). EDP obtained by tilting the sample by $14.8^{\circ}$, so as to observe the $\gamma$-phase along the [100] zone axis. Two different phases contribute to this complex EDP: the $\gamma$ phase and another cubic phase $\beta_{1}$ phase with lattice parameter $a_{\beta 1}=5.72 \AA=2 / 3 a_{\gamma}$, both aligned along their [100] direction. The two lattices are superimposed on the EDP (dotted lines: $\gamma$ phase; solid lines: $\beta_{1}$ phase).

phase observed in this micrograph in the vicinity of the surface of the coating has more complex ORs with the substrate and the $\beta$ phase in this case (Table II). Finally, Fig. 8(a) shows an EDP of the substrate in A3 orientation 


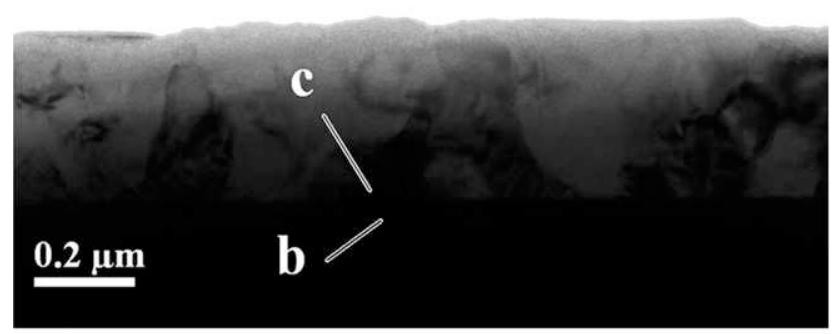

(a)

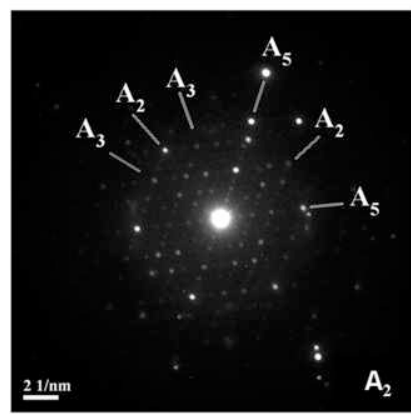

(b)

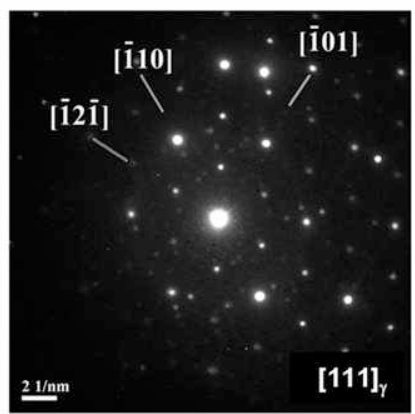

(c)

and Fig. 8(b) shows the ORs between the substrate and the $\beta$ phase at the interface. The OR is A3//[111 $]_{\beta}$. Table II summarizes the various ORs determined from Figs. 4 to 8.

To confirm these ORs, we use the stereographic projection proposed by $\mathrm{D}$. Shechtman for the icosahedral phase $^{14}$ superimposed on the projection of the cubic structure (either $\beta$ or $\gamma$ ), calculated with the crystallographic data from Villars and Calvert ${ }^{40}$ and using software CaRine 3.1. We first align the $\mathrm{A}_{2}$ substrate zone axis with the [111] zone axis of the film. Then the cubic stereographic projection is rotated around its zone axis so as to optimize the alignment of dense directions of the substrate and film. Among the various possible ORs, the two following ones offer the best matching:

$$
\begin{gathered}
\mathrm{A}_{2-\text { sub }} \|[111]_{\text {cubic }} \\
\mathrm{A}_{5 \text {-sub }} \|[-101]_{\text {cubic }} \\
\mathrm{A}_{2 \text {-sub }} \|[-110]_{\text {cubic }} \\
\mathrm{A}_{3 \text {-sub }} \|[-12-1]_{\text {cubic }}
\end{gathered}
$$

and

$$
\mathrm{A}_{2-\text { sub }} \|[111]_{\text {cubic }}
$$

FIG. 6. (a) Bright field micrograph of a sample with thickness ratio $t_{\mathrm{Al}} / t_{\mathrm{Cu}}=1.06$ and substrate oriented along an $\mathrm{A}_{2}$ axis. EDPs patterns of
(b) the quasicrystalline substrate, and (c) the $\gamma$-phase along the [111] axis.

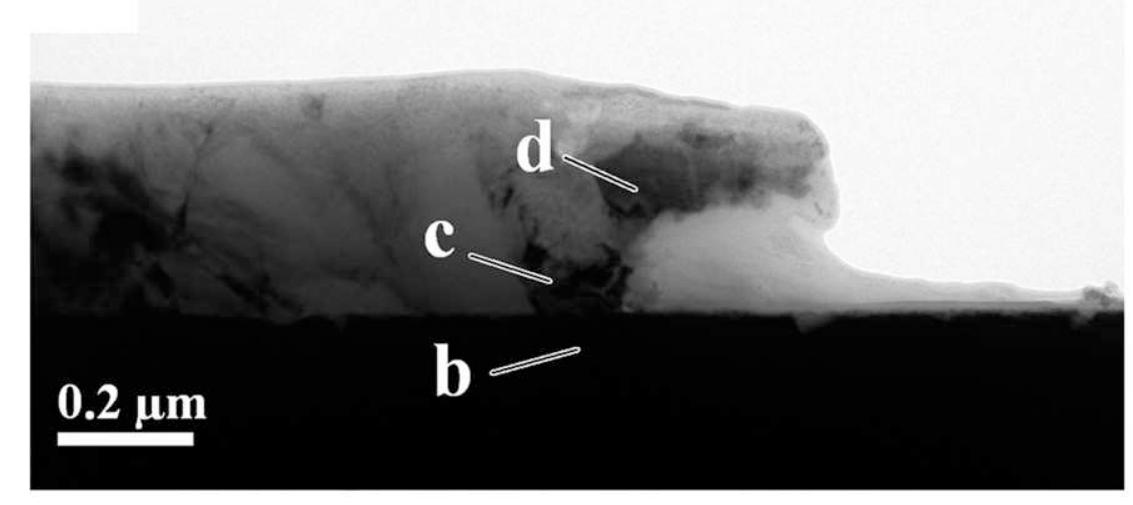

(a)

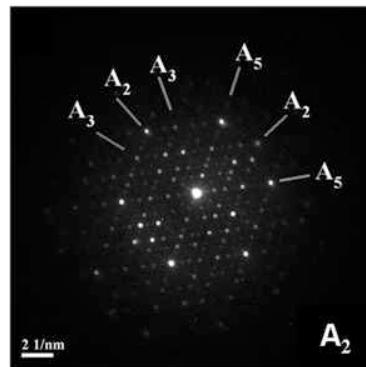

(b)

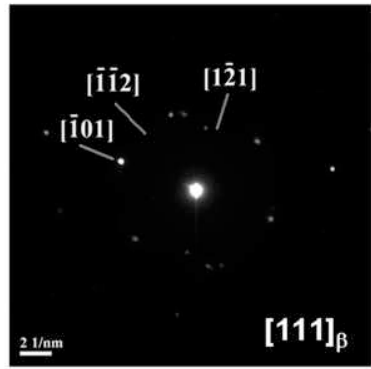

(c)

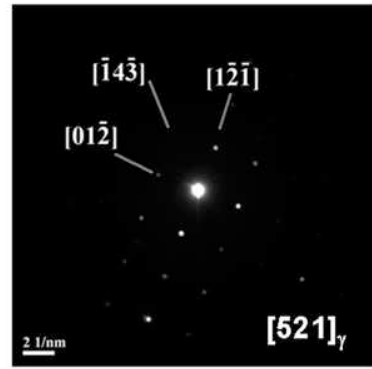

(d)

FIG. 7. (a) Bright field micrograph of a sample with thickness ratio $t_{\mathrm{Al}} / t_{\mathrm{Cu}}=1.06$ and substrate oriented along an $\mathrm{A}_{2}$ axis. (b) EDPs patterns of quasicrystalline substrate, $\beta$-phase along the [111] axis, and (c) $\gamma$-phase along the [521] axis. 

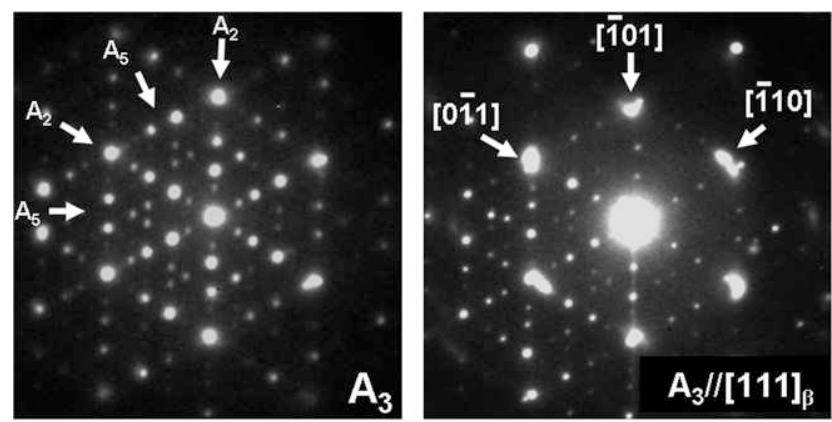

(a)

(b)

FIG. 8. (a) EDPs of the substrate in A3 orientation and (b) ORs between the substrate and the $\beta$ phase at the interface.

TABLE II. Orientation relationships determined from electron diffraction. Note that the $\gamma$ grain in [521] orientation is not in direct contact with the interface or the substrate.

\begin{tabular}{|c|c|c|c|}
\hline \multirow{2}{*}{$\begin{array}{l}\text { Zone axis of } \\
\text { the icosahedral } \\
\text { substrate }\end{array}$} & \multicolumn{2}{|c|}{ Interfacial relationships } & \multirow{2}{*}{$\begin{array}{c}\text { Film grain } \\
\gamma\end{array}$} \\
\hline & $\beta$ & $\gamma$ & \\
\hline $\mathrm{A}_{2}$ & $\begin{array}{l}{[111]_{\beta}} \\
\mathrm{A}_{5 \text { sub }} \|^{1-21}{ }_{\beta} \\
\mathrm{A}_{2 \text { sub }} \|[-1-12]_{\beta} \\
\mathrm{A}_{3 \text { sub }} \|[-101]_{\beta}\end{array}$ & $\begin{array}{l}{[111]_{\gamma}} \\
\mathrm{A}_{2 \text { sub }} \|[-110]_{\gamma} \\
\mathrm{A}_{3 \text { sub }} \|[-12-1]_{\gamma}\end{array}$ & $\begin{array}{l}{[521]_{\gamma}} \\
\mathrm{A}_{5 \text { sub }} \|^{1,2-1} \gamma \\
\mathrm{A}_{2 \text { sub }} \|[-14-3]_{\gamma} \\
\mathrm{A}_{3 \text { sub }} \|[01-2]_{\gamma}\end{array}$ \\
\hline $\mathrm{A}_{3}$ & $\begin{array}{l}{[111]_{\beta}} \\
\mathrm{A}_{2 \text { sub }} \text { II }[0-11]_{\beta} \\
\mathrm{A}_{2 \text { sub }} \text { II }[-101]_{\beta} \\
\mathrm{A}_{2 \text { sub }} \text { II }[-110]_{\beta}\end{array}$ & & \\
\hline $\mathrm{A}_{5}$ & $\begin{array}{l}{[111]_{\beta}} \\
\mathrm{A}_{2 \text { sub }} \|[10-1]_{\beta} \\
\mathrm{A}_{2 \text { sub }} \|[1-10]_{\beta}\end{array}$ & & $\begin{array}{l}{[111]_{\gamma}} \\
\mathrm{A}_{2 \text { sub }} \|[10-1]_{\gamma} \\
\mathrm{A}_{2 \text { sub }} \|^{1-10} \gamma\end{array}$ \\
\hline
\end{tabular}

$$
\begin{aligned}
& \mathrm{A}_{3-\text { sub }} \|[-101]_{\text {cubic }} \\
& \mathrm{A}_{2 \text {-sub }} \|[-1-12]_{\text {cubic }} \\
& \mathrm{A}_{5 \text {-sub }} \|[1-21]_{\text {cubic }}
\end{aligned}
$$

These results are in perfect agreement with the ORs determined experimentally from Figs. 6 and 7 and confirm the occurrence of a textured film. These relationships are also in agreement with the ones predicted by the different interface models between icosahedral phases and CsCl-type phases. ${ }^{47}$ In particular, it was shown that the coincidence site lattice at the $\mathrm{A} 5_{\mathrm{QC}} /[110]_{\beta}$ interface presents a relatively small mismatch that should correspond to a minimum in the interfacial free energy between the two phases. ${ }^{39,46}$ This orientation relationship is frequently encountered in ultrahigh vacuum studies of the fivefold surface of icosahedral phases. ${ }^{20}$

Most of the ORs reported in Table II are in agreement with previous observations of quasicrystal-crystal interfaces, except for the $A_{5} \|[111]_{\text {cubic }}$ relationship determined for substrate oriented normal to an $\mathrm{A}_{5}$ axis. This relationship is in contradiction with other ORs deter- mined for different substrate orientations, indicating that the $\mathrm{A}_{5}$ direction should be parallel to the $\left.<110\right\rangle$ and $<121>$ type directions. This particular interface could thus correspond to a metastable configuration. It is worth mentioning that this $\mathrm{A}_{5}$ zone axis was the only one we could access experimentally, although five additional $\mathrm{A}_{5}$ axes could in principle be investigated.

\section{CONCLUSIONS}

We have described the formation of $\mathrm{Al}-\mathrm{Cu}$ coatings of different crystallographic structures on various substrates by low temperature annealing of bilayers of specific thicknesses. In particular, we could successfully form the two CMA phases contained in the $\mathrm{Al}-\mathrm{Cu}$ phase diagram, including the $\gamma-\mathrm{Al}_{4} \mathrm{Cu}_{9}$ compound. A $1 \mu \mathrm{m}$ thick coating of this latter phase has been synthesized on the fivefold surface of an icosahedral Al-Pd-Mn single grain and the substrate-film interface was studied by TEM. Four different phases were identified. The interface mainly contains a $\beta$ phase of unknown composition with a lattice parameter $a=2.87 \AA$ whereas the film mainly contains the $\gamma$ phase with a lattice parameter $a=8.60 \AA$. An additional structure could be identified occasionally at the interface between the $\beta$ and $\gamma$ phases. This metastable $\beta_{1}$ structure links the two others with an intermediate lattice parameter of $a=5.72 \AA$ corresponding to $2 a_{\beta}$ and $2 / 3 a_{\gamma}$. Experimental ORs at the interface are confirmed through the superimposition of the stereographic projections of the phases and are in general agreement with the different models for quasicrystalcrystal interfaces as well as with relevant, earlier reports. Such orientation relationships between metallic $\beta$ and $\gamma$ phases and the quasicrystalline substrate are expected to promote the adherence of the coating. In addition, these metallic phases represent an intermediate degree of complexity between a quasicrystal and a simple metal, supporting the idea that such phases could be used as a buffer layer.

\section{ACKNOWLEDGMENTS}

This work has been supported by the European Network of Excellence on Complex Metallic Alloys (CMA) under Contract No. NMP3-2005-CT-500145 and by the French National Research Agency under Contract No. ANR-05-BLAN-0297-01.

\section{REFERENCES}

1. C. Dong: The $\delta-\mathrm{Al}_{4} \mathrm{Cu}_{9}$ phase as an approximant of quasicrystals. Philos. Mag. A 73, 1519 (1996).

2. C. Dong, Q.H. Zhang, D.H. Wang, and Y.M. Wang: Al-Cu approximant in the $\mathrm{Al}_{3} \mathrm{Cu}_{4}$ alloy. Eur. Phys. J. B 6, 25 (1998).

3. C. Dong, Q.H. Zhang, D.H. Wang, and Y.M. Wang: Al-Cu approximants and associated B2 chemical twinning modes. Micron 31, 507 (2000). 
4. V. Fournée, E. Belin-Ferré, and J.M. Dubois: Study of Al-Cu Hume-Rothery alloys and their relationship to the electronic properties of quasicrystals. J. Phys. Condens. Matter 10, 4231 (1998).

5. V. Fournée, I. Mazin, D.A. Papaconstantopoulos, and E. BelinFerré: Electronic-structure calculations of Al-Cu alloys: Comparison with experimental results on Hume-Rothery phases. Philos. Mag. B 79, 205 (1999).

6. L.D. Gulay and B. Harbrecht: The crystal structure of $\zeta-\mathrm{Al}_{3} \mathrm{Cu}_{4}$. J. Alloys Compd. 367, 103 (2004).

7. X.L. Ma, A. Rüdiger, H. Liebertz, U. Köster, and W. Liu: A new structural variant of the $\zeta-\mathrm{Al}_{3} \mathrm{Cu}_{4}$ an its orientation relationship with the cubic $\gamma-\mathrm{Al}_{4} \mathrm{Cu}_{9}$. Scr. Mater. 39, 707 (1998).

8. G. Trambly de Laissardière, Z. Dankházi, E. Belin, A. Sadoc, N.M. Duc, D. Mayou, M.A. Keegan, and D.A. Papaconstantopoulos: Experimental and theoretical electronic distributions in Al-Cu-based alloys. Phys. Rev. B 51, 14035 (1995).

9. G. Trambly de Laissardière, D. Nguyen-Manh, and D. Mayou: Electronic structure of complex Hume-Rothery phases and quasicrystals in transition metal aluminides. Prog. Mater. Sci. 50, 679 (2005).

10. J.M. Dubois: Basics of Thermodynamics and Phase Transitions in Complex Intermetallics, edited by E. Belin-Ferré (World Scientific, Singapore, 2008), pp. 1, 31.

11. E. Belin-Ferré and J.M. Dubois: Wetting of aluminium based complex metallic alloys. Int. J. Mater. Res. 97, 985 (2006).

12. J.M. Dubois: The applied physics of quasicrystals. Phys. Scr. T. 49A, 17 (1993).

13. J.M. Dubois, P. Brunet, and E. Belin-Ferré: Quasicrystals: Current Topics (World Scientific, Singapore, 2000), pp. 498, 532.

14. D. Shechtman, I. Blech, D. Gratias, and J.W. Cahn: Metallic phase with long-range orientational order and no translational periodicity. Phys. Rev. Lett. 53, 1951 (1984).

15. J.M. Dubois: Useful Quasicrystals (World Scientific, Singapore, 2005).

16. T. Duguet, J. Ledieu, J.M. Dubois, and V. Fournée: Surface alloys as interfacial layers between quasicrystalline and periodic materials. J. Phys. Condens. Matter 20, 314009 (2008).

17. H. Chen and S.M. Heald: Glancing angle EXAFS studies of $\mathrm{Cu}-\mathrm{Al}$ thin film interfaces. Physica B 158, 658 (1989).

18. M.R.F. Hurtado, J. Portillo, Y. Maniette, A.T. Adorno, and A.V. Benedetti: A complex structure in the $\left(\beta+\gamma_{0}\right)$ region of the $\mathrm{Cu}-\mathrm{Al}$ alloys. J. Alloys Compd. 280, 188 (1998).

19. H.G. Jiang, J.Y. Dai, H.Y. Tong, B.Z. Ding, Q.H. Song, and Z.Q. $\mathrm{Hu}$ : Interfacial reactions on annealing $\mathrm{Cu} / \mathrm{Al}$ mulilayer thin films. J. Appl. Phys. 74, 6165 (1993).

20. X.J. Liu, I. Ohnuma, R. Kainuma, and K.J. Ishida: Phase equilibria in the $\mathrm{Cu}$-rich portion of the $\mathrm{Cu}-\mathrm{Al}$ binary system. J. Alloys Compd. 264, 201 (1998).

21. C.B. Ene, G. Schmitz, T. Al-Kassab, and R. Kirchheim: Solid state reaction in sandwich-type $\mathrm{Al} / \mathrm{Cu}$ thin films. Ultramicroscopy 107, 802 (2007).

22. J. Geng and P. Oelhafen: Photoelectron spectroscopy study of Al$\mathrm{Cu}$ interfaces. Surf. Sci. 452, 161 (2000).

23. M. Mozetic, A. Zalar, T. Bogataj, I. Arcon, and R. Preseren: Comparison of AES and EXAFS analysis of a thin $\mathrm{Cu}_{x} \mathrm{Al}_{y}$ layer on Al substrate. Vacuum 50, 299 (1998).

24. M. Mozetic, A. Zalar, and M. Drobnic: Self-controlled diffusion of $\mathrm{Al}$ in $\mathrm{Cu}$ thin film. Vacuum 50, 1 (1998).

25. J.M. Vandenberg and R.A. Hamm: An in situ X-ray study of phase transformation in $\mathrm{Cu}-\mathrm{Al}$ thin film couples. Thin Solid Films 97, 313 (1982)

26. N. Bonasso, C. Petitot, D. Rouxel, and P. Pigeat: In situ control of AlCuFe thin film crystallization using optical pyrometry. Thin Solid Films 485, 8 (2005).
27. N. Bonasso and P. Pigeat: Preparation of Al-Cu-Fe ultra-thin quasicrystalline films without protective coatings by MBE: Influence of processing. Mater. Sci. Eng., A 349, 224 (2003).

28. N. Bonasso and P. Pigeat: Real time study of the growth of $i$-AlCuFe in very thin films obtained by simultaneous deposition of the components. J. Non-Cryst. Solids 334-335, 509 (2004).

29. N. Bonasso, P. Pigeat, D. Rouxel, and B. Weber: Effect of oxygen on the making of $\mathrm{AlCuFe}$ quasicrystalline coatings. Thin Solid Films 409, 165 (2002).

30. M. Cekada, P. Panjan, J. Dolinsek, A. Zalar, Z. Medunic, M. Jaksic, and N. Radic: Diffusion during annealing $\mathrm{Al} / \mathrm{Cu} / \mathrm{Fe}$ thin films. Thin Solid Films 515, 7135 (2007).

31. T. Grenet, F. Giroud, J.L. Joulaud, and M. Capitan: Formation of icosahedral $\mathrm{Al}-\mathrm{Cu}-\mathrm{Fe}$ quasicrystal in annealed thin multilayers. Philos. Mag. A 82, 2909 (2002).

32. C. Dong: The concept of the approximants of quasicrystals. Scr. Metall. Mater. 33, 239 (1995).

33. J.L. Murray: Al-Cu system. Int. Mater. Rev. 30, 211 (1985).

34. M. Bielmann, A. Barranco, P. Ruffieux, O. Gröning, R. Fasel, R. Widmer, and P. Gröning: Formation of $\mathrm{Al}_{4} \mathrm{Cu}_{9}$ on the 5-fold surface of icosahedral AlPdMn. Adv. Eng. Mater. 7, 392 (2005).

35. J.D.R. Buchanan, T.P.A. Hase, B.K. Tanner, P.J. Chen, L. Gan, C.J. Powell, and W.F. Egelhoff: Anomaleously large intermixing in aluminium-transition metal bilayers. Phys. Rev. B 66, 104427 (2002).

36. A. Bancel and P.A. Heiney: Icosahedral alloys: Phase purity and phason strains. J. Phys. Colloq. 47, 341 (1986).

37. Z. Zhang and K.H. Kuo: Local icosahedral order in nickel-titanium ( $\left.\mathrm{NiTi}_{2}\right)$ icosahedral quasicrystal. J. Microsc. 146, 313 (1987).

38. A. Letoublon: Diffuse scattering and phasons in icosahedral and modulated icosahedral Al-Pd-Mn phases. Ph.D. Thesis, Institut National Polytechnique de Grenoble, Grenoble, 2000, p. 226.

39. B. Bolliger, M. Erbudak, D.D. Vvedensky, M. Zurkirch, and A.R. Kortan: Surface structural transitions on the icosahedral quasicrystal $\mathrm{Al}_{70} \mathrm{Pd}_{20} \mathrm{Mn}_{10}$. Phys. Rev. Lett. 80, 5369 (1998).

40. P. Villars and L.D. Calvert: Pearson's Handbook of Crystallographic Data for Intermetallic Phases, Vol. 1 (ASM International, Materials Park, OH, 1998).

41. R. Hultgren, P.R. Desai, D.T. Hawkins, M. Gleiser, and K.K. Keiley: Selected Values of the Thermodynamic Properties of Selected Binary Alloys (American Society for Metals, Metals Park, OH, 1973).

42. A. Srivastava, K. Yu-Zhang, L. Kilian, J. Frigério, and J. Rivory: Interfacial diffusion effect on phase transitions in $\mathrm{Al} / \mathrm{Mn}$ multilayered thin films. J. Mater. Sci. 42, 185 (2007).

43. Z. Shen, M.J. Kramer, C.J. Jenks, A.I. Goldman, T. Lograsso, D. Delaney, M. Heinzig, W. Raberg, and P.A. Thiel: Crystalline surface structure induced by ion sputtering of Al-rich icosahedral quasicrystals. Phys. Rev. B 58, 9961 (1998).

44. J.A. Barrow, V. Fournée, A.R. Ross, P.A. Thiel, M. Shimoda, and A.P. Tsai: Photoemission studies of the sputter-induced phase transformation on the Al-Cu-Fe surface. Surf. Sci. 539, 54 (2003).

45. F. Shi, Z. Shen, D.W. Delaney, A.I. Goldman, C.J. Jenks, M.J. Kramer, T. Lograsso, P.A. Thiel, and M.A. van Hove: The surface structure of a beta- $\mathrm{Al}\left(\mathrm{Cu}_{1}-x \mathrm{Fe}_{x}\right)-(110)$ film formed on an $\mathrm{AlCuFe}$ quasicrystal substrate analyzed by dynamical LEED. Surf. Sci. 411, 86 (1998).

46. G.V.S. Sastry and P. Ramachandrarao: Transformation studies on vacancy ordered metastable phases in melt spun Al-Cu alloys, in Proceedings of the 4th International Conference on Rapidly Quenched Metals (1981).

47. E.J. Widjaja and L.D. Marks: Models for quasicrystal-crystal epitaxy. J. Phys. Condens. Matter 20, 314003 (2008). 